\title{
Oxygen content dependent etch rate of single polymer microparticles confined in the sheath region of a low pressure radiofrequency argon/oxygen plasma
}

Citation for published version (APA):

Schepers, L. P. T., IJzerman, W. L., \& Beckers, J. (2018). Oxygen content dependent etch rate of single polymer microparticles confined in the sheath region of a low pressure radiofrequency argon/oxygen plasma. Journal of Physics D: Applied Physics, 51(37), [375203]. https://doi.org/10.1088/1361-6463/aad5b4

\section{Document license:}

TAVERNE

DOI:

10.1088/1361-6463/aad5b4

Document status and date:

Published: 19/09/2018

\section{Document Version:}

Publisher's PDF, also known as Version of Record (includes final page, issue and volume numbers)

\section{Please check the document version of this publication:}

- A submitted manuscript is the version of the article upon submission and before peer-review. There can be important differences between the submitted version and the official published version of record. People interested in the research are advised to contact the author for the final version of the publication, or visit the DOI to the publisher's website.

- The final author version and the galley proof are versions of the publication after peer review.

- The final published version features the final layout of the paper including the volume, issue and page numbers.

Link to publication

\footnotetext{
General rights

- You may freely distribute the URL identifying the publication in the public portal. follow below link for the End User Agreement:

www.tue.nl/taverne

Take down policy

If you believe that this document breaches copyright please contact us at:

openaccess@tue.nl

providing details and we will investigate your claim.
}

Copyright and moral rights for the publications made accessible in the public portal are retained by the authors and/or other copyright owners and it is a condition of accessing publications that users recognise and abide by the legal requirements associated with these rights.

- Users may download and print one copy of any publication from the public portal for the purpose of private study or research.

- You may not further distribute the material or use it for any profit-making activity or commercial gain

If the publication is distributed under the terms of Article $25 \mathrm{fa}$ of the Dutch Copyright Act, indicated by the "Taverne" license above, please 
PAPER

Oxygen content dependent etch rate of single polymer microparticles confined in the sheath region of a low pressure radiofrequency argon/oxygen plasma

To cite this article: L P T Schepers et al 2018 J. Phys. D: Appl. Phys. 51375203

View the article online for updates and enhancements.
Related content

Spatio-temporal evolution of the dust particle size distribution in dusty argon rf plasmas

Carsten Killer, Matthias Mulsow and André Melzer

Kinetic Mie ellipsometry to determine the time-resolved particle growth in nanodusty plasmas

Sebastian Groth, Franko Greiner, Benjamin Tadsen et al.

In situ nanoparticlediagnostics by multiwavelength Ravleigh-Mie

scatteringellipsometry G Gebauer and J Winter

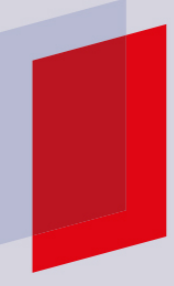

\section{IOP ebooks}

Bringing you innovative digital publishing with leading voices to create your essential collection of books in STEM research. Start exploring the collection - download the first chapter of every title for free. 


\title{
Oxygen content dependent etch rate of single polymer microparticles confined in the sheath region of a low pressure radiofrequency argon/oxygen plasma
}

\author{
L P T Schepers ${ }^{1} \oplus$, W L IJzerman ${ }^{2,3}$ and J Beckers ${ }^{1,4}$ \\ ${ }^{1}$ Department of Applied Physics, Eindhoven University of Technology, PO Box 513, 5600 MB \\ Eindhoven, Netherlands \\ 2 CASA, Eindhoven University of Technology, PO Box 513, 5600 MB Eindhoven, Netherlands \\ 3 Philips Lighting, High Tech Campus 7, 5656 AE Eindhoven, Netherlands
}

E-mail: j.beckers@tue.nl

Received 17 May 2018, revised 12 July 2018

Accepted for publication 25 July 2018

Published 13 August 2018

\begin{abstract}
To study the etching of polymer microparticles confined in low pressure radiofrequency plasmas, the size and refractive index of single $2 \mu \mathrm{m}$ particles are experimentally obtained as a function of both time and oxygen content $(0 \%-50 \%)$ added to the argon background gas. The etch rate was found to depend heavily on the oxygen $\left(\mathrm{O}_{2}\right)$ content, especially for mixtures with low fractions of $\mathrm{O}_{2}$. As expected the etch rate was found to be close to zero in absence of $\mathrm{O}_{2}$ and increases to a value of $2 \mathrm{~nm} \mathrm{~min}^{-1}$ for $0.5 \% \mathrm{O}_{2}$ and to roughly $3.5 \mathrm{~nm} \mathrm{~min}-1$ for $5 \% \mathrm{O}_{2}$. Above $5 \% \mathrm{O}_{2}$ the etch rate saturates. It is shown that these results are consistent with a steady state etch model taking the effects of both atomic oxygen and positive ions into account.
\end{abstract}

Keywords: microparticle etching, plasma sheath, argon/oxygen plasma

(Some figures may appear in colour only in the online journal)

\section{Introduction}

Increasingly frequently, plasmas are utilized to synthesize and modify small nano- to micrometer sized particles $[1,2]$. Whereas these so-called 'dusty plasmas' are most often thought of in terms of growth [3, 4], i.e. plasma enhanced polymerization to trigger nanoparticle formation $[5,6]$, particle coagulation into larger particles $[6,7]$ and steady state particle growth due to deposition of mainly plasma-generated radicals on their surface [8,9], etching of the particle material by the surrounding plasma may be significant as well, but has appeared hard to study.

It is especially the permanent negative charge, which plasma-immersed particles obtain due to the difference in mobility between (positive) ions and electrons, together with the plasma potential which is positive in relation with the

\footnotetext{
${ }^{4}$ Author to whom any correspondence should be addressed.
}

surroundings, that can make the particles being confined for considerable amounts of time in the plasma volume. Being confined in the space charge layer of plasma (for micrometer sized particles [10]), these negatively charged particles are subjected to influx of plasma-produced radicals and violent bombardment by ions. Both radicals and impinging ions may be responsible for plasma etching, often in a synergetic manner [11]. Well known etching species (etchants) are for example species containing fluor (e.g. $\mathrm{CF}_{4}$ ) and species containting chloride (e.g. $\mathrm{CL}_{2}$ ), for example to the end of etching silicon targets [12]. Oxygen is a well known etchant for treating organic polymers $[13,14]$.

In this paper, we present the experimentally determined oxygen content dependent etch rate of polymer microparticles confined in the sheath region of a low pressure radiofrequency (RF) argon/oxygen plasma. To this end, we utilize the previously developed in situ and angular-resolved Mie scattering technique in combination with a routine to fit these data to 


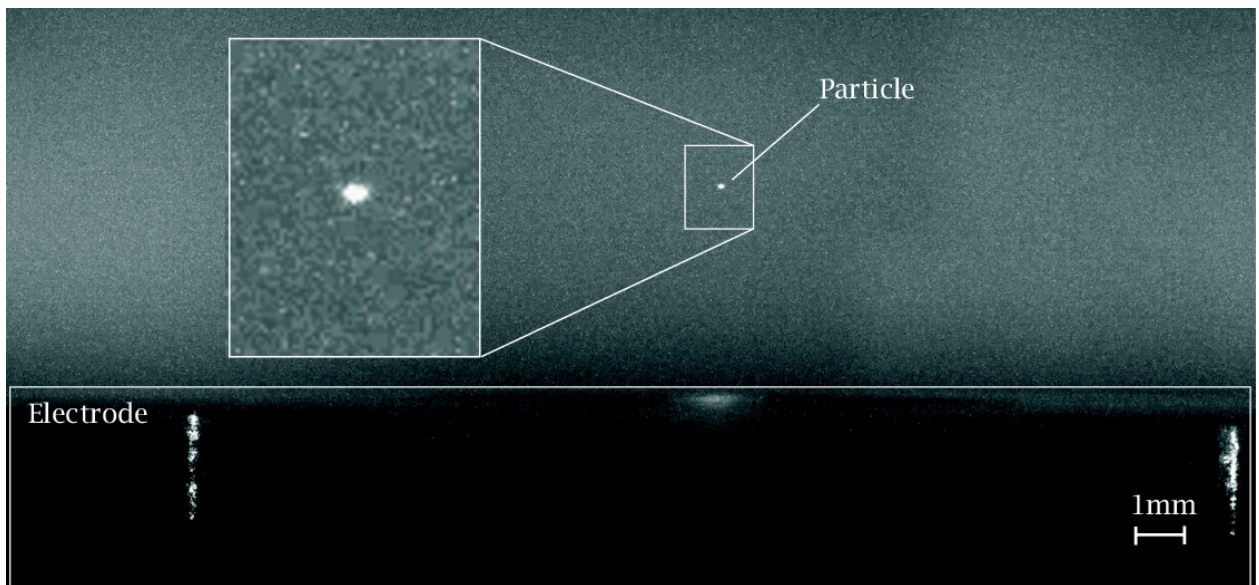

Figure 1. Picture of a microparticle confined in the plasma sheath near the powered electrode.

a Mie scattering model [15]. This method delivers the size, refractive index and etch rate under controlled plasma conditions where for instance oxygen content is changed.

The conducted experiments are relevant (I) to the field of complex and dusty plasma physics since polymeric (e.g. melamine formaldehyde (MF)) particles are often used in experiments [16-19] where they are often subject to plasma etching (e.g. due to non-sublime vacuum conditions), and (II) to all studies and experiments involving plasma etching of polymeric surfaces using oxygen (containing) plasmas $[11,20,21]$.

This manuscript is organized as follows. Section 2 will eleborate briefly on the concept of plasma etching and the equilibrium confinement position of micrometer-sized particles in the plasma sheath. Section 3 discusses the used experimental setup and the Mie scattering diagnostics. Section 4 contains the experimental results with as main result the obtained etch rates of a single plasma confined polymeric microparticle as a function of $\mathrm{O}_{2}$ content in a background argon (Ar) plasma. For analysis of the experimental results, an etch model is introduced in this section as well. Finally, discussion and conclusions drawn from this work are discussed in section 5.

\section{Etching and confinement position of microparticles}

Oxygen plasmas can be used to etch a variety of organic polymers [22]. Although the exact mechanism of polymer etching by oxygen is not fully understood, atomic oxygen is believed to play a dominant role. Etch rates of polymer surfaces have been found to be correlated with the density of $\mathrm{O}$ and etching has been observed downstream, but in the vicinity of, oxygen plasmas where atomic oxygen still persist [14]. [13]:

Plasma etching can be divided in four types of mechanisms

(I) Physical sputtering by high energetic ions (at least a few tens of eV). Surface material is ejected due to the impact of the ion. This mechanism occurs mainly at low pressure, where the mean free path is sufficiently long and ions can be accelerated to high energies $(>100 \mathrm{eV}$ in industrial applications). As no chemistry is involved, possibilities of selecting the material to be etched are limited and the etch rates are low.

(II) Chemical etching by plasma produced species. This is a purely chemical mechanism, where a neutral species reacts with the surface after which the reaction product is volatile. Due to the purely chemical mechanism, this process is highly selective, but is isotropic as the movement of the etching species has no preference direction. In this process, the role of the plasma is merely the creation of the etching species.

(III) Ion enhanced etching. In this process, neutral reactive etchants chemically react with the surface only when enough energy is supplied by ions bombarding the target. Here, an anisotropic mechanism is combined with the selectivity of chemical etching.

(IV)Inhibitor ion enhanced etching uses the anisotropic movement of ions in combination with chemical etching. In this case, however, an inhibitor species is added which forms a protective layer on the substrate. Etching only takes place where ion bombardment removes the protective layer, allowing a quick etchant to etch the unprotected area on the substrate.

When macroscopic particles (typically $10 \mathrm{~nm}$ to $100 \mu \mathrm{m}$ ) are immersed in a plasma, they acquire a negative charge. Due to this negative charge, the particles can be confined by the electric fields which are typically present in the plasma sheath [10]. The position on which the forces on a particle (besides the aforementioned electric force, mainly gravity and the ion drag force are dominant) cancel each other provides insight in the plasma dynamics in the plasma sheath [17]. This allows the use of microscopic particles as probes in gas discharges.

Our previous measurements in [15] have been performed with a contaminated argon RF discharge, thus containing a small fraction of oxygen, due to a non-zero base pressure as is always the case in laboratory and industrial plasmas. By actively adding oxygen to a pristine argon (as is done in the current work) discharge, among others (e.g oxygen ions) the etchant $\mathrm{O}$ is produced and the etch mechanism can be further clarified right at the confinement position of the particle. It is 


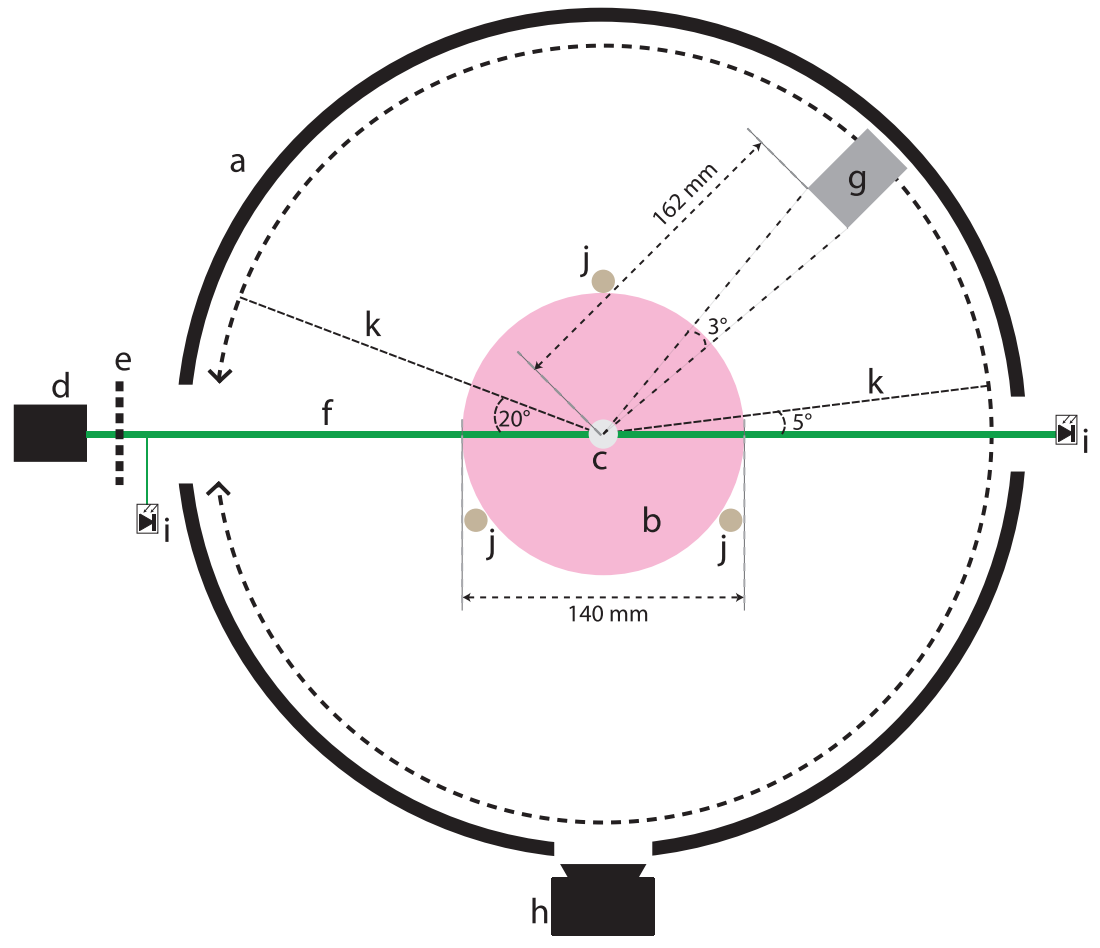

(a)

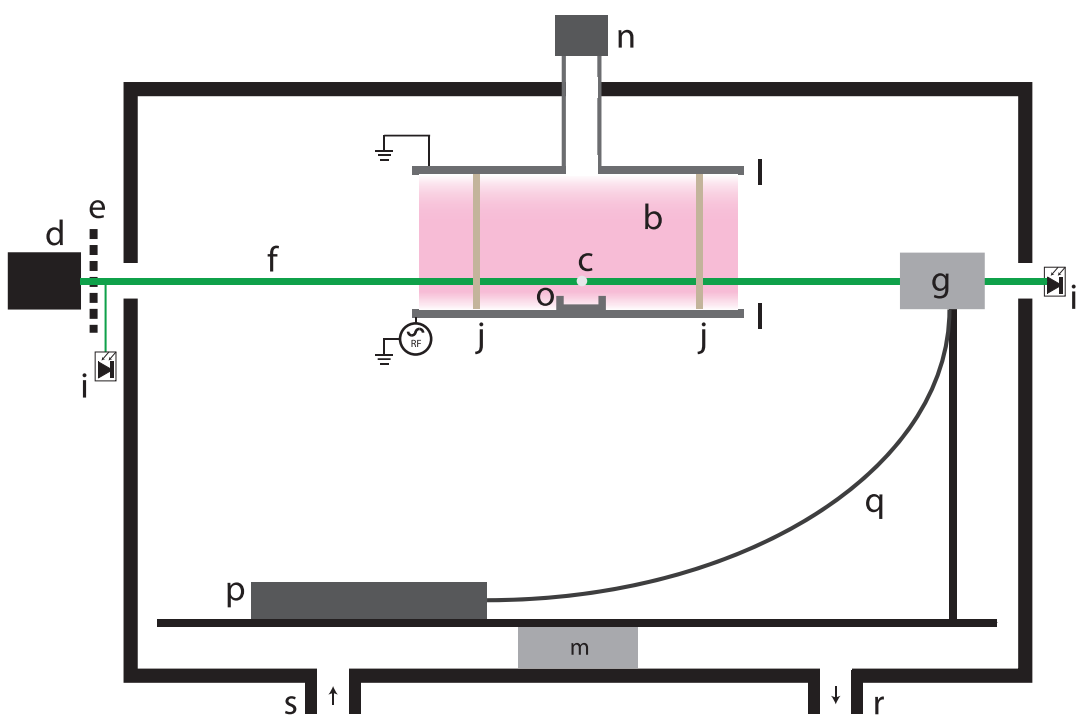

(b)

Figure 2. Schematic view of the setup, cross sections from the top and from the side. (a) Vacuum vessel with three viewports. (b) Plasma. (c) Microparticle. (d) Laser. (e) Polariser, polarising the light perpendicularly to the scatter plane. (f) Laser beam. (g) Collector rotating around the plasma. (h) Camera. (i) Photodiodes. (j) Pillars between electrodes. (k) Detection boundaries. (l) Electrodes. (m) Stepper motor to rotate the collector around the plasma. (n) Particle dispenser. (o) Modification of electrodes for particle confinement. (p) Spectrometer. (q) Optical fiber. (r) Connection to pumping system. (s) Gas inlet. Adapted from [15]. (a) Top view. (b) Side view.

known that oxygen is able to etch polymer particles (like MF) [23]. A picture of a confined particle is shown in figure 1.

\section{Methods}

The experimental setup used for the current investigation is similar to that described in detail in a previous article [15]. In this section, an overview of the most import aspects of the used setup is provided. Figure 2 gives a schematic representation of the setup. For additional details of the setup the reader is directed to [15].

A radio frequent $(13.56 \mathrm{MHz})$ discharge is created between two horizontally aligned parallel plates at a pressure of $16 \mathrm{~Pa}$. The stainless steel electrodes have a diameter of $140 \mathrm{~mm}$ and are aligned $44 \mathrm{~mm}$ apart, while the bottom one is powered and the top one is grounded. The plasma power dissipation is fixed at $10 \mathrm{~W}$. 
A single spherical melamine formaldehyde (MF) particle is confined in the plasma sheath above the bottom electrode. Particles are stored in a particle container which is situated above the plasma. By shaking the container, particles will fall through a hole in the container's bottom and fall further through a larger hole in the top electrode after which the particles are confined in the plasma. The amount of particles leaving the particle suspender can be regulated by shaking the container more or less strongly. By tuning this process, it is possible to immerse a single particle. A full description of the workings of this particle dispenser is given in [24].

The bottom electrode is modified to allow the confinement of a single particle. As described in section 2, gravity and the different plasma forces acting on the particle allow particle confinement in the direction perpendicular to the electrode, which is parallel with the gravitational acceleration. The bottom electrode is designed with a circular indent to also allow horizontal confinement of the particle. This indent is $3 \mathrm{~mm}$ deep and has a radius of $5 \mathrm{~mm}$. Due to this indent, a net horizontal electric force is acting on the particle when it is out of the center of the indent, keeping the particle in the center. According to the supplier [25], the used particles have a radius of $2.35 \mu \mathrm{m}$ and a refractive index of 1.68 .

The particle size is measured by measuring laser light scattered from the particle angularly resolved. A diode laser emitting light with a wavelength of $532 \mathrm{~nm}$, which is polarised perpendicularly with respect to the scatter plane, is used as light source for the incident beam. A detector is placed inside the vacuum chamber and can rotate around the plasma so that it measures the light scattered from the particle in the angle range from $5^{\circ}$ to $160^{\circ}$ degrees.

The oxygen content is controlled by argon and oxygen flows by two separate flow controllers. The vessel has been pumped down to a base pressure of $5 \cdot 10^{-6} \mathrm{mBar}$.

The particle size and refractive index are determined based on the measured angular scatter profile. Given the size relative to the wavelength and the refractive index of a spherical particle, Mie theory [26] is valid under these conditions. The inverse method for determining the relevant particle parameters is applied here. Because measuring the scatter profile typically takes an hour, the etch rate of a single particle can be determined next to the refractive index and the particle size. This method comes down to fitting the position of peaks and valleys in the profile to those in Mie theory, using three fit parameters (refractive index, initial particle size and etch rate). A full description of this method is described in [15].

Figures 3-14 show the measured scatter profiles which are fitted with the described method. The oxygen content is varied and is given in the caption of the figures. The positions of peaks and values which are used in the algorithm are marked by the grey rings. In the angle domain marked in grey, visual access to the particle is blocked in the setup. Note that during the angular profile scan the particle size is decreasing due to etching and that the analysis method incorporates this feature self-consistently. The angular scatter profile is used to determine the size, the refractive index and the etch rate of the confined particle.

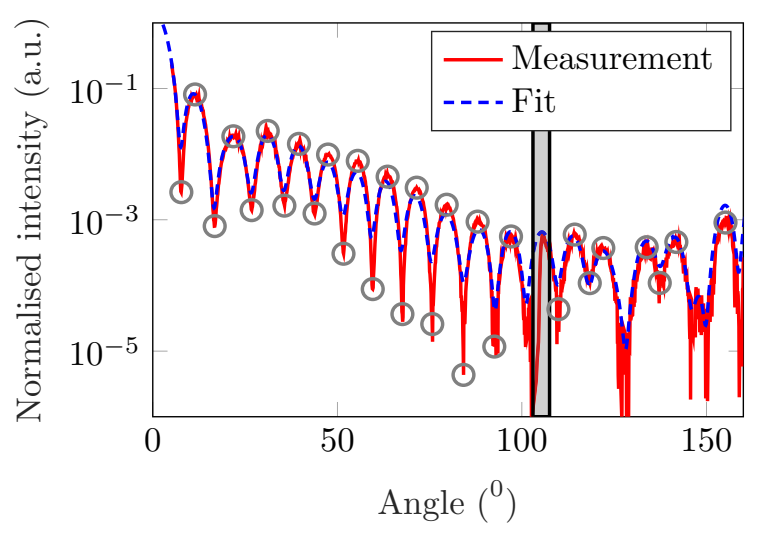

Figure 3. Oxygen content is $0 \%$.

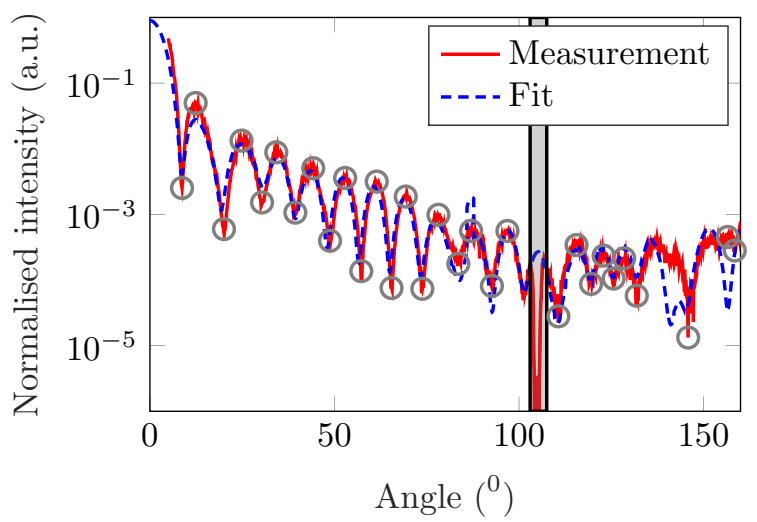

Figure 4. Oxygen content is $0.5 \%$.

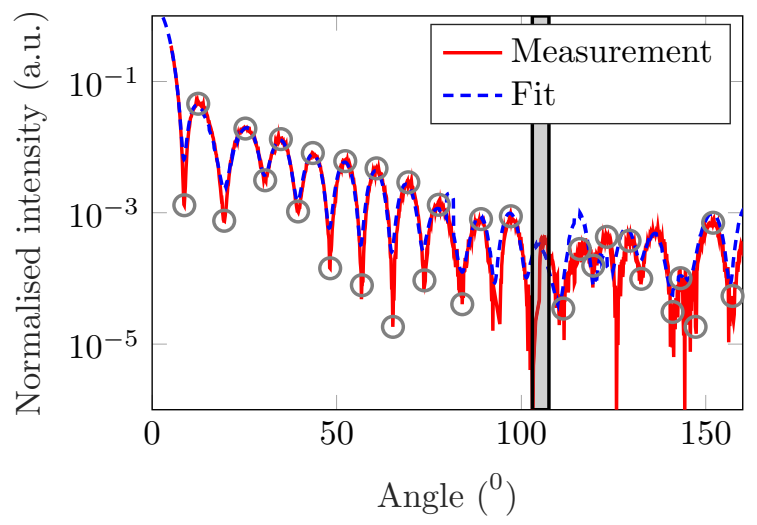

Figure 5. Oxygen content is $1 \%$

\section{Results}

The etch rate of a single particle is measured as a function of the oxygen content in an argon/oxygen admixture. After the results are presented, the etch mechanism is shortly discussed. For each measurement with a different amount of oxygen a new particle is injected, so that the different measurements are comparable. Note that deviation in the initial particle size between different measurements is taken into account. The refractive index of the particles is hypothesized real, as is motivated in [15].

Figure 15 shows the etch rate of particles as function of the oxygen content. The dashed line is placed to guide the eye 


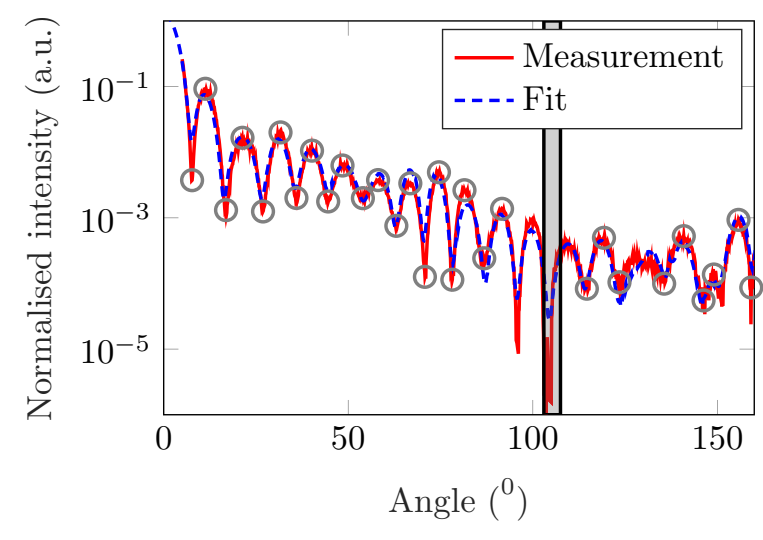

Figure 6. Oxygen content is $2 \%$.

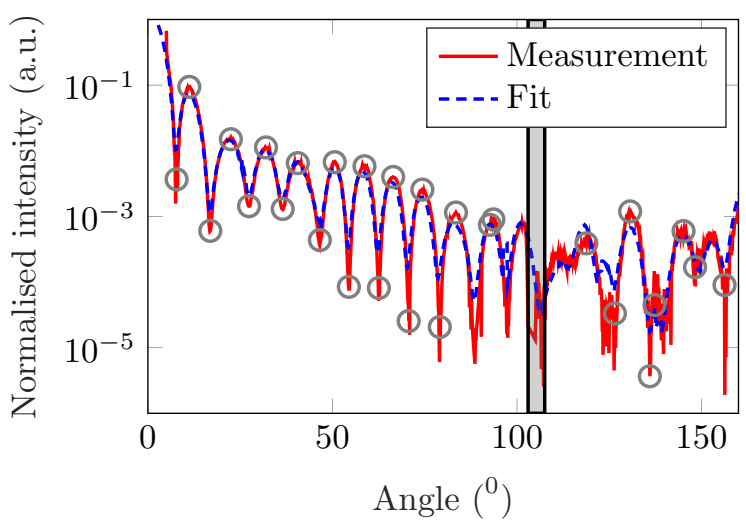

Figure 7. Oxygen content is $3 \%$.

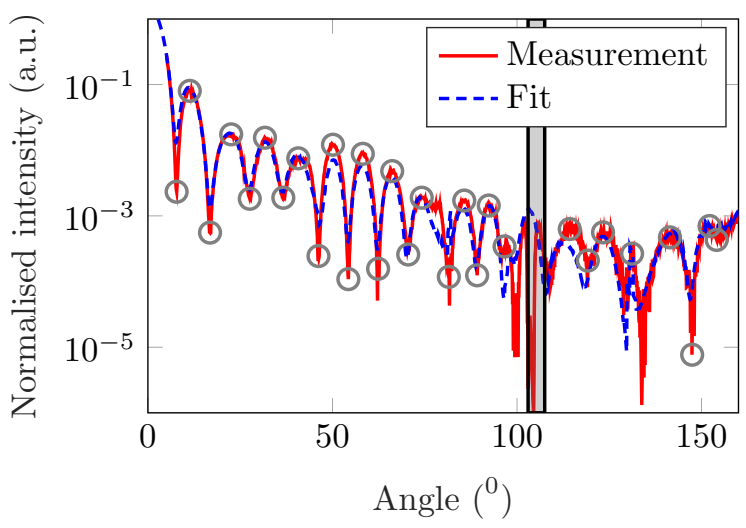

Figure 8. Oxygen content is $4 \%$.

and show similarities with the model later in this section. It is clear that the fraction of oxygen influences the etch rate significantly. In a pure argon plasma, minimal etching takes place. Adding a small amount as only $0.5 \%$ of oxygen, immediately increases the etch rate to about $2 \mathrm{~nm} \mathrm{~min}{ }^{-1}$. Further increasing the oxygen content raises the etch rate further, but it is leveled at about $4.7 \mathrm{~nm} \mathrm{~min} \mathrm{~m}^{-1}$ for oxygen contents higher than $20 \%$.

The dependence of the etch rate on the fraction of oxygen gas is not uncommon for polymer etching of bulk material, but it is the first time it is found for a plasma confined microparticle. With respect to etching of bulk materials, Murillo et al have found a similar sub-linear trend in the etch rate of polymers as fraction of the oxygen content in an argon admixture

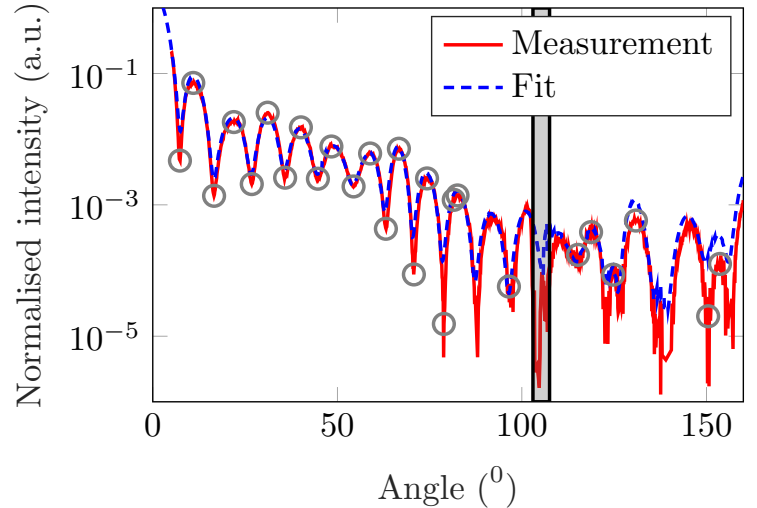

Figure 9. Oxygen content is $5 \%$.

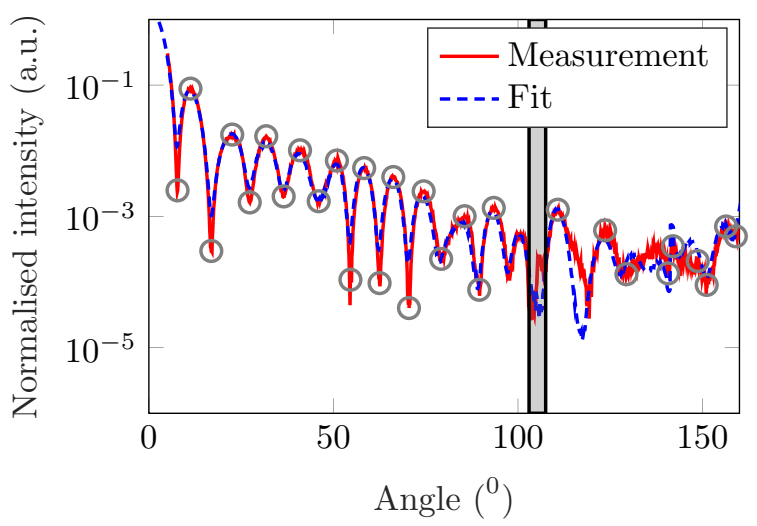

Figure 10. Oxygen content is $10 \%$.

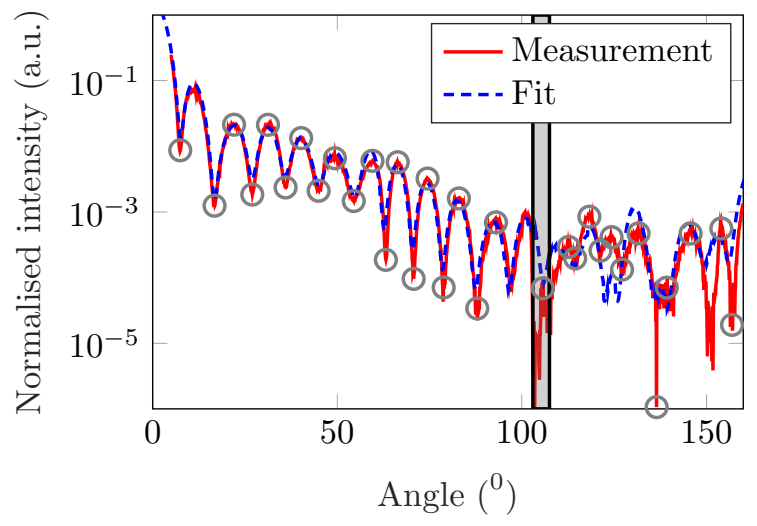

Figure 11. Oxygen content is $15 \%$.

[11]. Joubert et al found that the etch rate of sample polymers saturates for increasing atomic oxygen density in oxygen/ nitrogen admixtures [21]. In both of these investigations, it was found that the etch rate increased with the provided ion energy.

To give an explanation for the leveling of the etch rate at higher oxygen content in figure 15, the etch process itself is discussed in more detail. Assuming that atomic oxygen in synergy with ion bombardment is responsible for etching [11], the full mechanism can be explained in three sequential steps. Step 1: adsorption. Atomic oxygen is created in the plasma by dissociation of molecular oxygen and is adsorbed at the particle's surface. Step 2: etch reaction. Ions impacting on the particle provide energy for the adsorbed etchant to undergo 


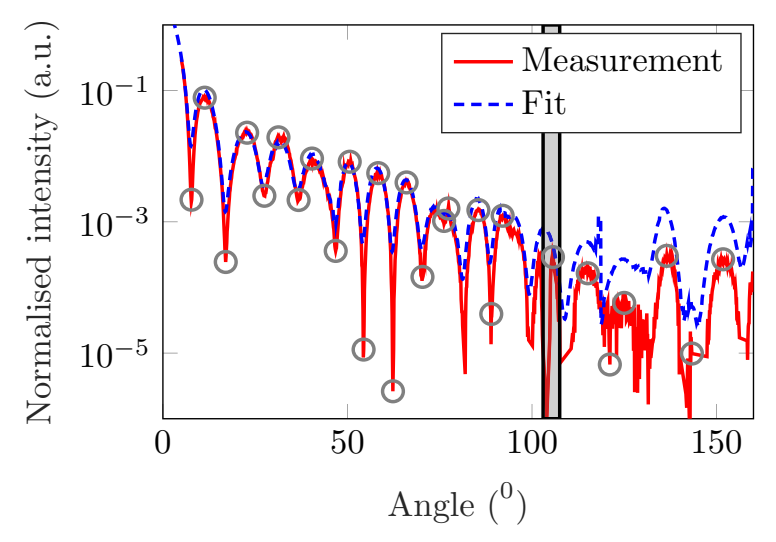

Figure 12. Oxygen content is $20 \%$.

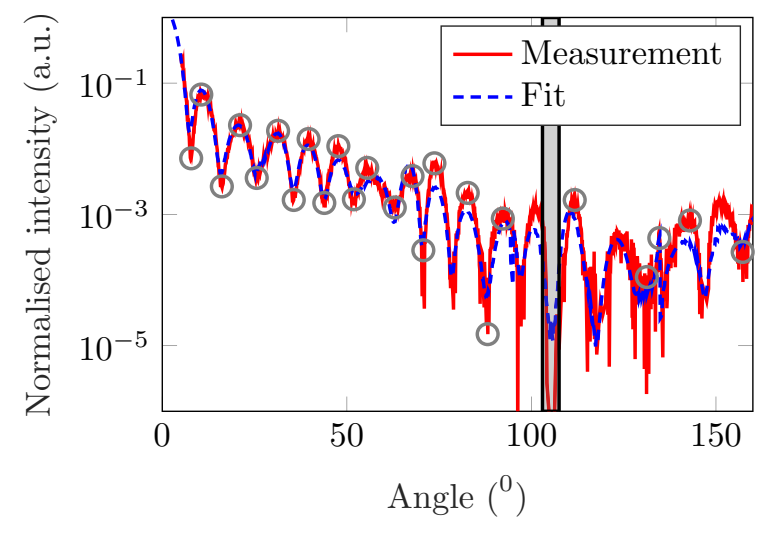

Figure 13. Oxygen content is $35 \%$.

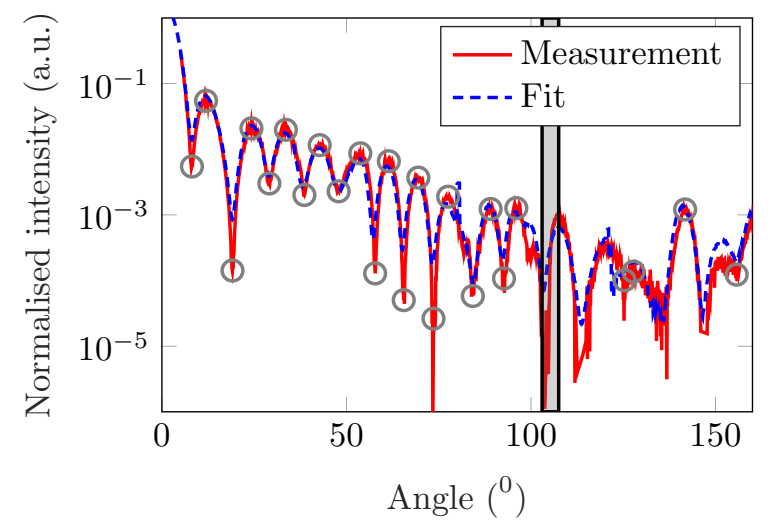

Figure 14. Oxygen content is $50 \%$.

the etch reaction and create etch products. Step 3: desorption. The etch products leave the particle by desorption [13].

These steps are described qualitatively by the etch model of Bray and Rhinehart [27]: at the surface, a certain amount of sites for etching are present which may be in different states. The vacant sites $\left(S_{\mathrm{v}}\right)$ are available for adsorption of an etchant species or etch product, the other sites are occupied by either adsorbed etchants $\left(S_{\mathrm{O}}\right)$ or adsorbed etch products $\left(S_{\mathrm{p}}\right)$. The sum of these states gives the total amount of sites $S=S_{\mathrm{v}}+S_{\mathrm{O}}+S_{\mathrm{p}}$. In a stationary situation, the amount of occupied sites is given by:

$$
\frac{\mathrm{d} S_{\mathrm{O}}}{\mathrm{d} t}=r_{\mathrm{a}}-r_{\mathrm{r}}=k_{\mathrm{a}} \Gamma_{\mathrm{O}} S_{\mathrm{v}}-k_{\mathrm{r}} \Gamma_{\mathrm{i}} S_{\mathrm{O}}=0,
$$

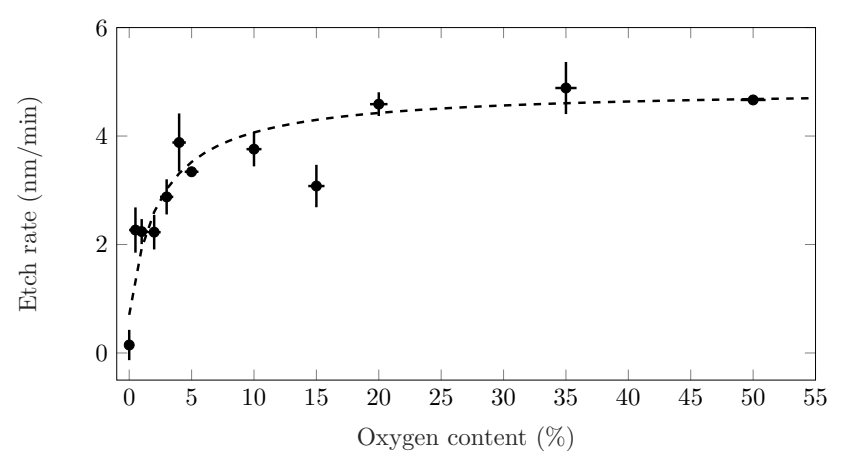

Figure 15. Etch rate as function of oxygen content in the discharge. For all measurements the pressure is $16 \mathrm{~Pa}$ and the power $10 \mathrm{~W}$. The dashed line is placed to guide the eye; it is a fit through the data points following the function $Y(X)=a+\frac{b c d X}{c+d X}$, neglecting the data points at $4 \%$ and $15 \%$ of oxygen.

$$
\frac{\mathrm{d} S_{\mathrm{p}}}{\mathrm{d} t}=r_{\mathrm{r}}-r_{\mathrm{d}}=k_{\mathrm{r}} \Gamma_{\mathrm{i}} S_{\mathrm{O}}-k_{\mathrm{d}} S_{\mathrm{p}}=0
$$

where $r_{\mathrm{a}}, r_{\mathrm{r}}$ and $r_{\mathrm{d}}$ are the rates at which respectively the adsorption, etch reaction and desorption steps take place. $k_{\mathrm{a}}$, $k_{\mathrm{r}}$ and $k_{\mathrm{d}}$ represent coefficients for the respective processes. $\Gamma_{\mathrm{O}}, \Gamma_{\mathrm{i}}$ and $\Gamma_{\mathrm{p}}$ give the flux to the particle for respective etchants $\mathrm{O}$, ions $\mathrm{i}$, and etch products $\mathrm{p}$. Backwards reactions (e.g. desorption of etchants for step (1) are neglected. Solving equations $(1 a)$ and $(1 b)$ for $S_{\mathrm{O}}$ yields:

$$
S_{\mathrm{O}}=\frac{k_{\mathrm{a}} \Gamma_{\mathrm{O}} S}{k_{\mathrm{r}} \Gamma_{\mathrm{i}}+\frac{k_{\mathrm{a}} k_{\mathrm{r}}}{k_{\mathrm{d}}} \Gamma_{\mathrm{O}} \Gamma_{i}+k_{\mathrm{a}} \Gamma_{\mathrm{O}}} .
$$

Assuming that the etch reaction step is the limiting step and the desorption step to be very fast $\left(k_{\mathrm{d}} \gg k_{\mathrm{r}}\right.$ [27]), the etch rate $r_{r}$ can be written as:

$$
r_{\mathrm{r}}=k_{\mathrm{r}} \Gamma_{\mathrm{i}} S_{\mathrm{O}}=\frac{k_{\mathrm{a}} k_{\mathrm{r}} S \Gamma_{\mathrm{i}} \Gamma_{\mathrm{O}}}{k_{\mathrm{r}} \Gamma_{\mathrm{i}}+k_{\mathrm{a}} \Gamma_{\mathrm{O}}} .
$$

This expression can be clarified by taking the limits of the atomic oxygen flux and the ion flux. For constant coefficients, taking the ion flux goes towards infinity, the etch rate is determined by the atomic oxygen flux and vice versa.

This model can be used to explain the results presented above in figure 15. Apparently, the increase in flux of etchant species towards the particle for increasing oxygen content dominates the total etch rate only for low values of the oxygen contents. For oxygen contents roughly above 5\%, creation of additional neutral etchants leaves the particles etch rate unaltered apparently. This indicates that the etch rate for high oxygen contents is limited by the limited energy flux provided by the impinging ions.

The initial particle size and the refractive index of the particle vary for each particle. These values are given, together with the etch rate, in table 1 . Figure 16 gives a graphical representation of the variation in initial particle size and refractive index and the difference to the supplier specified values (square marker). The deviation from the specified value is relatively large compared to the spread of the data points for both the refractive index and the particle size. 
Table 1. The found fit parameters for each scan together with corresponding error. $m_{\mathrm{k}}$ represents the refractive index, $\frac{\mathrm{d} a}{\mathrm{~d} t}$ gives the etch rate and $a_{0}$ is the initial particle size.

\begin{tabular}{llrr}
\hline$\left[\mathrm{O}_{2}\right](\%)$ & $m_{\mathrm{k}}$ & $\frac{\mathrm{d} a}{\mathrm{~d} t}(\mu \mathrm{m})$ & \multicolumn{1}{c}{$a_{0}\left(\mathrm{~nm} \mathrm{~min}^{-1}\right)$} \\
\hline 0.0 & $1.639 \pm 0.005$ & $0.15 \pm 0.3$ & $2.149 \pm 0.006$ \\
0.5 & $1.642 \pm 0.007$ & $2.2 \pm 0.4$ & $2.061 \pm 0.009$ \\
1.0 & $1.643 \pm 0.002$ & $2.2 \pm 0.2$ & $2.057 \pm 0.005$ \\
2.0 & $1.646 \pm 0.006$ & $2.2 \pm 0.3$ & $2.146 \pm 0.007$ \\
3.0 & $1.634 \pm 0.007$ & $2.9 \pm 0.3$ & $2.154 \pm 0.007$ \\
4.0 & $1.634 \pm 0.004$ & $3.9 \pm 0.5$ & $2.16 \pm 0.012$ \\
5.0 & $1.637 \pm 0.005$ & $3.3 \pm 0.09$ & $2.172 \pm 0.002$ \\
10.0 & $1.631 \pm 0.004$ & $3.8 \pm 0.3$ & $2.169 \pm 0.007$ \\
15.0 & $1.634 \pm 0.013$ & $3.1 \pm 0.4$ & $2.167 \pm 0.009$ \\
20.0 & $1.631 \pm 0.004$ & $4.6 \pm 0.2$ & $2.176 \pm 0.005$ \\
35.0 & $1.630 \pm 0.013$ & $4.9 \pm 0.5$ & $2.211 \pm 0.011$ \\
50.0 & $1.631 \pm 0.002$ & $4.7 \pm 0.09$ & $2.122 \pm 0.002$ \\
\hline
\end{tabular}

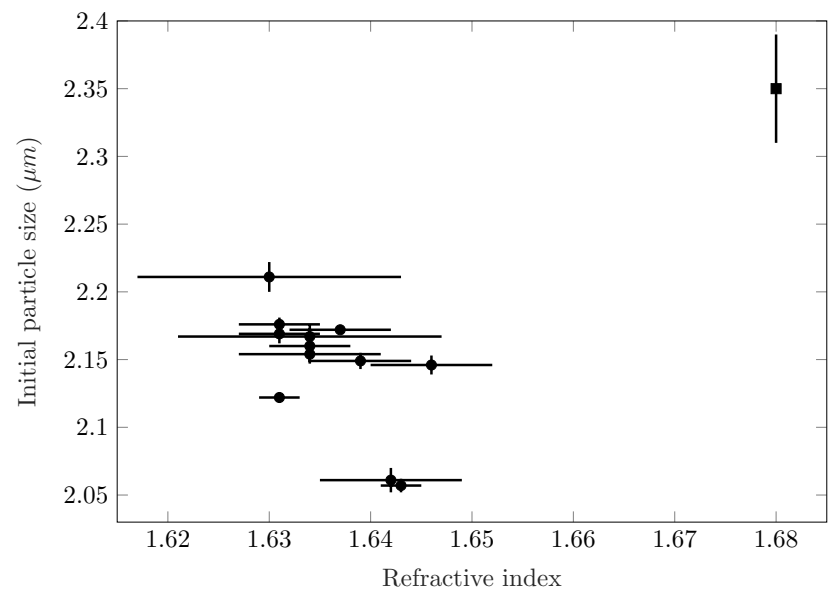

Figure 16. Graphical representation of the found initial particle size and refractive index. The square marker represents the specified values.

\section{Conclusions}

The etch rate of a microparticle in an oxygen containing discharge is not proportional with the oxygen content in the background gas, for oxygen content higher than $20 \%$ the etch rate reaches a maximum of $4.7 \mathrm{~nm} \mathrm{~min}{ }^{-1}$. This effect can be explained by the contribution of the positive ions, assuming that the density of atomic oxygen increases with the oxygen content in the background gas. For small amounts of oxygen, the atomic oxygen flux dictates the etch rate. The etch rate is dictated by the ion flux when oxygen is abundant.

Additionally, this research shows that data on the particle radius more accurate than given by the supplier is essential for quantitative utilisation of the microparticle as probes for the plasma sheath. This is because small variations on particle radius have a significant influence on the plasma-particle dynamics under investigation (mainly the electric field, particle charge and ion drag force). It is shown in this work that measured particle properties are different from the values provided by their suppliers. Consequently, the radius of MF particles measured by angularly resolved Mie scattering is found approximately $10 \%$ lower than specified. Also the refractive index is measured to be lower than specified.

The influence of gas contamination in the discharge should not be underestimated in time consuming measurements. Small amounts of contamination (e.g. oxygen, water) could enhance etching of mainly polymer particles. When this is the case, the particle size and mass are not constant. Mass losses should be determined and taken into account for correct interpretation of the measurements, especially for measurements that take a relatively long time.

\section{Acknowledgements}

This work is part of the research programme of the Foundation for Fundamental Research on Matter (FOM), which is part of the Netherlands Organisation for Scientific Research (NWO).

\section{ORCID iDs}

L P T Schepers (1) https://orcid.org/0000-0003-4293-3987

\section{References}

[1] Boufendi L, Jouanny M C, Kovacevic E, Berndt J and Mikikian M 2011 Dusty plasma for nanotechnology J. Phys. D: Appl. Phys. 44174035

[2] Sankaran R M and Kortshagen U 2015 Special issue on plasma synthesis of nanoparticles J. Phys. D: Appl. Phys. 48310301

[3] Bouchoule A 1999 Dusty Plasmas, Chemistry and Technological Impacts in Plasma Processing (New York: Wiley)

[4] Berndt J, Kovačević E, Stefanović I, Stepanović O, Hong S H, Boufendi L and Winter J 2009 Some aspects of reactive complex plasmas Contrib. Plasma Phys. 49 107-33

[5] De Bleecker K, Bogaerts A, Gijbels R and Goedheer W 2004 Numerical investigation of particle formation mechanisms in silane discharges Phys. Rev. E 69056409

[6] van de Wetering F M J H, Beckers J and Kroesen G M W 2012 Anion dynamics in the first 10 milliseconds of an argonacetylene radio-frequency plasma J. Phys. D: Appl. Phys. 45485205

[7] van de Wetering F M J H, Brooimans R J C, Nijdam S, Beckers J and Kroesen G M W 2015 Fast and interrupted expansion in cyclic void growth in dusty plasma J. Phys. D: Appl. Phys. 48035204

[8] Cao J and Matsoukas T 2002 Deposition kinetics on particles in a dusty plasma reactor J. Appl. Phys. 92 2916-22

[9] Beckers J, Stoffels W W and Kroesen G M W 2009 Temperature dependence of nucleation and growth of nanoparticles in low pressure $\mathrm{Ar} / \mathrm{CH} 4 \mathrm{RF}$ discharges J. Phys. D: Appl. Phys. 42155206

[10] Douglass A, Land V, Qiao K, Matthews L and Hyde T 2012 Determination of the levitation limits of dust particles within the sheath in complex plasma experiments Phys. Plasmas 19013707

[11] Murillo R, Poncin-Epaillard F and Segui Y 2006 Plasma etching of organic material: combined effects of charged and neutral species Eur. Phys. J. Appl. Phys. 37 299-305

[12] Donnelly V M and Kornblit A 2013 Plasma etching: yesterday, today, and tomorrow J. Vac. Sci. Technol. A 31050825 
[13] Manos D M and Flamm D L 1989 Plasma Etching and an Introduction (New York: Academic)

[14] d'Agostino R 1990 Plasma Deposition, Threatment and Etching of Polymers (New York: Academic)

[15] Schepers L P T, Beckers J and IJzerman W L 2018 Determination of microparticle characteristics in an etching plasma Contrib. Plasma Phys. 1-10

[16] Kersten H, Deutsch H, Stoffels E, Stoffels W and Kroesen G 2003 Plasmapowder interaction: trends in applications and diagnostics Int. J. Mass Spectrom. 223-4 313-25

[17] Beckers J, Ockenga T, Wolter M, Stoffels W W, Van Dijk J, Kersten H and Kroesen G M W 2011 Microparticles in a collisional rf plasma sheath under hypergravity conditions as probes for the electric field strength and the particle charge Phys. Rev. Lett. 106 1-4

[18] Annaratone B M, Antonova T, Thomas H M and Morfill G E 2004 Diagnostics of the electronegative plasma sheath at low pressures using microparticles Phys. Rev. Lett. 93 3-6

[19] Douglass A, Land V, Matthews L and Hyde T 2011 Dust particle charge in plasma with ion flow and electron depletion near plasma boundaries Phys. Plasmas 18083706
[20] Akinoglu E M, Morfa A J and Giersig M 2014 Understanding anisotropic plasma etching of two-dimensional polystyrene opals for advanced materials fabrication Langmuir: ACS J. Surf. Colloids 30 12354-61

[21] Joubert O, Pelletier J and Arnal Y 1989 The etching of polymers in oxygen-based plasmas: a parametric study J. Appl. Phys. 65 5096-100

[22] Vesel A and Semenič T 2012 Etching rates of different polymers in oxygen plasma Mater. Tehnol. 46 227-31

[23] Stoffels W, Stoffels E, Swinkels G, Boufnichel M and Kroesen G 1999 Etching a single micrometer-size particle in a plasma Phys. Rev. E 59 2302-4

[24] Beckers J 2011 Dust particle(s) (as) diagnostics in plasmas PhD Thesis Eindhoven University of Technology

[25] Microparticles gmbh (http://microparticles.de/en/ eigenschaften) (Accessed: 27 September 2016)

[26] Bohren C F and Huffman D R 1983 Absorption and Scattering by Small Particles (New York: Wiley)

[27] Bray R P and Rhinehart R R 2001 A simplified model for the etch rate of novolac-based photoresist Plasma Chem. Plasma Process. 21 149-61 